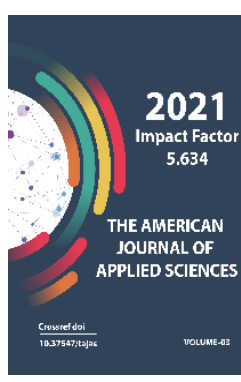

Journal Website: http://usajournalshub.c om/index,php/tajas

Copyright: Original content from this work may be used under the terms of the creative commons attributes 4.0 licence.

\section{The Culture Of Interpersonal Communication In The Family As A Prerequisite For Spiritual And Physical Development Of A Person}

Murotmusaev K.B.

Candidate Of Medical Sciences, Associate Professor, Psychology And Humanities Department, Jizzakh Branch Of M. Ulugbek National University Of Uzbekistan

Kholida Erkinboyeva

2nd Year Student, Psychology And Humanities Department, Jizzakh Branch Of M. Ulugbek National University Of Uzbekistan

\title{
ABSTRACT
}

The culture of relationships and the clarity of educational attitudes in the family is laid down consciously by parents as early as the prenatal period of a child's development. The highest mission of family education, the little school of Love - is the fullest revelation of the sources of spirituality in the young person.

\section{KEYWORDS}

Culture, human spiritual development, communication, family

\section{INTRODUCTION}

The subject of the study is communication in the family. The purpose of the study is to To reveal the specifics of communication in the family in the context of the conditions of spiritual and physical human development.
In today's multicultural world, young people in today's multicultural world are increasingly faced with young people in today's multicultural world are increasingly faced with the choice of "What to be?" The image of man 
in the preceding totalitarian and authoritarian eras was set by state ideology and limited For instance, "the code of the builder of Communism", the image of the Komsomol hero, the image of the "ideal German soldier", etc., are well known. How is the image of behavior shaped in the modern generation of young people?

It is this question that we bring forward as a target for the study. research. The scientific search is based on the author's many years of experience in of professional medicine and the study of traditional oriental techniques Improvement of the person and development of interpersonal relations. Practical The task of this research consists in giving recommendations on the basis of personal experience and scientific knowledge to give recommendations for systematic formation value-purpose attitudes in a young person in the family environment.

Without denying the importance of state institutions in the process of establishing a culture of interpersonal communication, I believe that the leading role in this sphere belongs to is the family. Neither schools nor any other social institutions possess such The power of Love, trust, and the power of parental authority. of parental authority. The only question is how parents can preserve and strengthen The question is how can we preserve and strengthen the foundation of family upbringing, the continuity of the accumulated spiritual experience?

In recent decades, marked by social instability and cultural fragmentation, a new generation of young people has grown up, In recent decades, a new generation of young people, exposed only to different subcultures and with little knowledge of traditional culture principles. What is especially worrisome is that the foundations of this generation's of the worldview of this generation is laid in most cases by the media. The foundation of this generation's worldview is laid, in most cases, by the mass media, the street environment, and publicly available and poorly trusted information from the Internet.

\section{THE MAIN FINDINGS AND RESULTS}

The family as the bearer of the ideological and goal-oriented attitudes the family is either relegated to the background in the educational process, or its values are denied altogether, values are denied altogether. Why does this happen? Why do we as parents often lose credibility with our children? The question is extremely complicated and multifaceted. There is only one point I want to make in this presentation: Are parental views and attitudes of interest to children, are the values applicable, Are the values inculcated by the family applicable in today's rapidly changing world?

Are we able to grow spiritually and physically ourselves, fitting into the paradigms of the new century, engaging our children in this children with this process? Or should we acknowledge that the child has a richer experience of spiritual self-knowledge and can even share their spiritual quests with their parents spiritual quest?

Unfortunately, in today's families, it is common for children, even when they are close to adults, to be excluded from the The children say that they experience a lack of attention and, more dangerously, a lack of respect and trust for themselves. lack of attention and, 
more dangerously, a lack of respect and trust. In connection with this, an increase in inadequate self-esteem, feelings of loneliness, cynicism and even violent tendencies. Psychologists also confirm that The modern generation of parents is characterized by an overt demonstration of Negative personality traits: frequent display of nervousness on various occasions, even insignificant ones, increased irritability, withdrawn, authoritarian, confrontational, and, at the same time, unreasonable indulgence of child and adolescent caprices.

This in no way contributes to stimulate positive interpersonal intrafamilial relationships and The authoritarian approach is not conducive to the development of positive interpersonal and intra-familial relationships. Authoritarian, Monological style of upbringing is viewed in modern conditions as unproductive.

In the East, the upbringing of a child is traditionally regarded as one as a kind of work of the soul, as a responsible opportunity to nurture not only The child's upbringing is traditionally regarded as a kind of soul work, a responsibility to nurture not only another life but also to strengthen oneself spiritually in the new creative role of father or mother. In my practice of psychological improvement I have successfully I have successfully combined the traditional knowledge of the East, embodied in the wisdom of Sufism, and I have successfully combined the traditional knowledge of the East, embodied in the wisdom of Sufism. Social work with adolescents.

It is obvious that the personality is formed depending on all spheres of family life: the family life, the spiritual and moral aura of the family, and the interpersonal type of interaction between older family members, the family, their attitude toward children. Thus, the ultimate purpose of family upbringing is the fullest disclosure of the sources of spirituality in the young person. Depending on which facet of spiritual of a person's spiritual qualities will be shaped more vividly in the family-positive or negative-that is how a person will manifest himself or herself. that is how a person will manifest himself in the system of social interactions. Not It is no coincidence that in the East they say that only the family can raise a family man!

The traditional family structure was always based on hierarchical The traditional family structure was always based on the hierarchical authority of the father. and care. But the modern style of urbanized and technocratic life, the change in of values, the focus on career advancement not only for men, but also for women excessive material prosperity, and high social status have led to the disintegration of the family structure that had been established and time-tested for centuries time-honored family patterns.

As a consequence, there were also disorders in the emotional and moral family unity, in the shift of hierarchical dependencies, in the simplification of the father's role, in the the growth of spiritual weakness of both parents and children. So we have identified a whole series of problems that have a common root: the lack of sincerity and love in in family relationships! In my opinion, one of the major obstacles to of interpersonal communication in many families is the atmosphere of violence that reigns between between all the members of the family. 
The child, while still in the womb, picks up falseness, anxiety, parental anger, perceiving such a family environment as hostile, leading to spiritual degradation. The interesting thing is that if even one family member, or even a pet, is capable of sincerely giving others True Love, it is a chance for the whole family to be strengthened, to cleanse oneself of spiritual "garbage" and start moving on the spiritual path.

Here are some practical tips for parents to revive a traditional culture of interpersonal communication:

The life of our ancestors, including its family aspect, was strictly The family life was strictly rhythmic, subject to a single cycle of natural laws. The type of family activities, i.e. family life was supported by a system of traditions, ceremonies and holidays. Family life was supported by a strict system of traditions, ceremonies and joint holidays. Unfortunately, members of of modern families have different social schedules of daily of everyday life, different professions, aptitudes, interests.

It would be very useful to remember, to resurrect family customs, to introduce at least a few traditions, maybe linking them to the seasons of the year. perhaps tying them to the seasons of the year. For example, summer vacations together at least for a week the whole family spends together, working for the good of the family and the clan. Family and clan work. Beneficial effect of unselfish help to neighbors, Joint holidays for all the children. It is necessary to teach the younger generation to give their efforts unselfishly, and in their lifetime!
In this joint action family harmony is revived, the child gets a feeling of "a reliable parental shoulder, strengthens the authority of the elders. It is necessary to consciously Avoid all forms of disharmony in relations. Eliminate Distressing criticism for the child, even in a joking form, and to base one's Actions, thoughts, and speech only on goodwill and benevolence in all situations, even if one of the family members is wrong. I recommend making such changes, starting with your speech, especially the timbre of your voice and your gaze. The most soothing, calm tone of voice and a gentle, positive look are most acceptable. Once again let me emphasize again that these are states that parents should develop in themselves by acting purposeful and conscious, in the course of joint psychophysical meditative exercises, or by listening to spiritual music, reading special literature.

Family life must not only be rhythmically aligned with The family's life should not only be rhythmically structured according to revived traditions, but also a unified spiritual foundation should be laid. In this, a special role belongs to the father, for it is he who determines the spiritual path of the family ship. The authority of the father will be increased and strengthened by That children will be able to see the success and priority of his life But this position should be responsible and sincere in the first place sincere. Lying in spiritual matters is most dangerous! And secondly, such a position should be constant, not depending on the vogue of the time and and the momentary orientations of society. I would especially emphasize that the education of boys should be aimed at developing a sense of responsibility for their thoughts and and actions, for the family, for the country, etc. 
Family life is only full and dynamic when it is filled with mother's love. Parents need to learn to clearly distinguish between the feeling of blind love, which only causes infantilism and social dependence in children, from sincere parental love that supports the child's spiritual and and physical growth. I will express a paradoxical, controversial idea, but it is very important: A child is capable of effective selfimprovement from the moment of conception, in the intrauterine period of its development. Parents must clearly understand that It is they who establish the culture of interpersonal communication in their offspring, and not not through moralizing, boring conversations about the right way of life (although the role of words in upbringing is also important), but parents can lay the foundation of culture spiritual development of the foetus with their kind thoughts, a positive attitude, and deliberate actions together in the family.

In the East it is said that the father educates to a greater extent by deeds, by personal example, and the mother by a kind word, a wise parable, a fairy tale, a conversation. By example, and the mother by a kind word, a wise parable, a fairy tale, a conversation. It is she who "leads" the child and supports in all difficulties on the "path of purification of the heart. The main qualities that, in my opinion, must be consciously cultivated The main qualities that I think a woman who is going to become a wife and a mother should consciously cultivate in herself are tenderness, forgiveness, solicitude, caring, and humility.

Based on my many years of experience as a doctor, I will address another important aspect of family life is the psycho-physical health of all family members. Nowadays a lot of literature is devoted to this problem, and media reports, etc., are devoted to this problem. In this presentation I would like to I would like to specify from what period it is necessary to begin forming a culture of of health. Alas, in the European civilization a man has only lost in a hospital bed or, even worse, in a wheelchair, begins to understand the value of a strong and active body.

As a physician, I am convinced, aided by my family's experience, that the key to health is in a conscious way of life, in the constant painstaking control of one's behavior and thoughts, a subtle analysis of one's emotions, the elimination of negative feelings and the cultivation of highly positive ones, in the purposeful the purposeful formation of stable spiritual interests in the whole family! This is what is fundamentally This is fundamentally important: a person lives and develops in the bosom of the family since birth. This is his or her daily spiritual and material support. It is not so important whether the family is full or incomplete. whether a family is full or incomplete it is spiritually stable status of people living together that matters. The family is created to meet not just one or two, but a whole set of vital human needs. The family, therefore, unlike other small groups, unions and corporations, unites the whole integrity of its existence, whereas whereas, for example, the members of the production team unite only their professional interests.

More than any other social formation, the family The family has a unique ability to connect personal - collective - public interests through its multifunctionality and ability to to cultivate the physiological and psychological needs of the individual, through its capacity for self-development as an inseparable cell of the great social organism called society. Therefore, 
the fullness and measure responsibility for the physical and spiritual-moral health of the child rests with Parents from the moment they reach out to each other, from the moment they They think about creating a family union and about giving birth to a new life - their future child.

In support of my conclusions I will refer to the statement Hazrat Inayat Khan stating that "most people are convinced that to be spiritual means to do wonders, to see extraordinary things, amazing

And only a few know how simple it is, to be spiritual means to be natural" [1, p. 215]. I will add to this statement by saying that to be healthy means to be a natural, physically and spiritually perfect person. Such This understanding must be inculcated in a child even before he or she is born prenatal education, prenatal inculcation of the culture of health, i.e. This understanding must be inculcated in the child before birth through prenatal education and the culture of health, i.e., through a sustained and purposeful relationship between mother and father unborn baby. In our concept of prenatal formation foundation of health, we do not view the unborn infant separately from the mother and even avoid calling it a "fetus," or an "embryo," as something totally unconscious, unformed.

The relationship with the child during the foetal period should be given more conscious importance, with the infant's spiritual and psychological development being ensured by both mother and father. In our practice, techniques that affect the unborn child are not applicable. We do not use methods for the unborn child, but the psycho-emotional state of the mother during the pregnancy is very important during pregnancy is very important and needs to be influenced in the direction of The mother's psycho-emotional state during pregnancy is very important and should be influenced in the direction of creating positivity, togetherness with the baby, feeling its mood.

Oriental practice attaches great importance to the spiritual state of the father during the whole period of the wife's pregnancy. This is important because according to Eastern worldview, the mother forms the infant's body and his psycho-physical status, while the father contributes to the formation of his child's spirit and "lays down" in the child's the more active and pure the father's thoughts on his child of his child, the more viable and successful the child will be in the future baby!

European medicine also talks about conscious preparation for conception and childbirth, Unfortunately, in our society there is an entrenched view that only a healthy a healthy nutrition, controlled physical effort and a positive attitude of the mother during pregnancy contributes to the correct development of the foetus during pregnancy contributes to the proper development of the foetus. The fathers, on the other hand, are often are either avoided altogether from the process of supervising their wives' pregnancies, or understand their role as the breadwinner of the family. In my opinion the idea is that this is not enough.

Parents should jointly make conscious preparations long before parents should consciously prepare for pregnancy long beforehand. It is especially important for young people It is especially important for 
young people who are about to start their lives and have their first sexual experiences.

A woman should think about pregnancy at least a year and a half in advance, i.e. think about her nutrition, adjust her mindset, assess her body's The state of the body's internal systems, mentally cleansing the reproductive It means to think about a pregnancy for at least a year and a half, to correct her nutrition, to clear her internal systems and fertile organs, to get rid of fears and negative pregnancy assumptions pregnancy. The father must carry out such work at least six months before conception child. It is a family and collective approach that is important in this difficult process It is the family approach and the commitment to the health of the unborn child that is important - the awareness of every action, words and thoughts of young parents!

I am a strong advocate of natural childbirth, preferably at home, because the birth process is one of the most important character-building events in a person's life. Surgical interventions, especially Caesarean section, which is fashionable in the West, creates fear, It may also lead to suicidal tendencies among adolescents and a reduction of a person's inner self. Often during childbirth a woman only thinks about her fears, her fear of pain and the possible negative consequences for her health alone. But she is responsible for the baby's health and life, especially as the pain passes quickly, but the character of the little one will be very hard to change later on.

The practical experience of Ukrainian specialists who have set up an antenatal centre at the Centre of Clinical Genetics and Prenatal Diagnostics in Kharkiv is of interest. Its staff, including paediatricians, neonatologists, geneticists and molecular biologists, are convinced that parents' attitudes can influence both the physical and psycho-emotional state of the baby. And in this centre the geneticists deal with the prevention of diseases in children long before they are born.

As practice shows, through classes at this centre, prenatal treatment and prenatal education of the child can significantly reduce the risk of transmitting hereditary family diseases and weaken the effect of pathological genes on the developing organism. Psychologists work with the most "problematic" couples to teach them how to communicate with their unborn child [3]. Specialists believe that the unborn child begins to react to the outside world from about 8-9 weeks of pregnancy, it even detects individual sound and taste preferences, which it actively signals. The modern psychologist V.M. Livshits states that the child also reacts sensitively to the mother's thoughts and changes of her emotions, i.e. "the unborn child already has consciousness, which is clearly recorded by researchers starting from six months of age" [3].

The successful cooperation of specialists from different fields, medical doctors, genetic biologists and psychologists is another confirmation of the fact that perinatal medicine and perinatal psychology have a promising development. In the last third of the twentieth century, there has been an upsurge of interest in prenatal and perinatal studies. The International Study Group on Prenatal Psychology (Vienna, 1971, initiated by G.H. Graber), the International Association of Prenatal and Perinatal Psychology and Medicine (Austria, 1986, ISPPM President Rupert Linder, MD (Germany)), the Russian 
Association of Perinatal Psychology and Medicine (APPM, Russia, Ivanovo, 1994) were established.

President of the Russian Association of Pre and Perinatal Development, Dr. Nina Chicherina), international journals have been published in English and German, and since 2004 the journal Perinatal Psychology and Parenthood Psychology has been published in Russia, and international congresses have been held. The International Society of Perinatal and Perinatal Psychology and Medicine (ISPPM) has grown in more than 30 years of experience into a respected world-class organisation with more than 500 experts from 10 countries in Europe alone. It has offices in 10 countries, including England, Greece, Poland, Hungary, Slovakia, Croatia, Serbia, Switzerland, Austria, Australia, The Netherlands, Spain, Israel.

The objectives of the work are to bring together the most important European scientific research and the latest methods of scientific knowledge from other continents and to coordinate, share and transfer truly unique information to the entire world community on the problems of prenatal medicine and psychology. The main objectives include such as the study of the basics of the integration of sciences - in obstetrics, neonatology, psychology, psychotherapy, sociology, genetics, physics and other disciplines, which contributes to the early prevention of bodily and spiritual developmental disabilities in the pre and perinatal phases of the child.

Further development of therapies and research in these fields of science based on indepth knowledge of prenatal development helps new generations of people to improve the quality of their lives, to give birth to children more already the XVII International Congress of the International Society of Prenatal and Perinatal Psychology and Medicine (ISPPM) and the VI All-Russian Congress of Pre- and Perinatal Psychology, Perinatology and Psychotherapy of the AllRussian Association of Pre- and Perinatal Development (RAPPD) [6].

Going deeper into the history of the issue, it should be noted that The theoretical foundations of perinatal psychology were laid by the American perinatal psychology was founded by the American researcher Stanislav Groff, who developed the perinatal matrix theory. According to Groff, the forming consciousness of the unborn baby contains four fundamental matrixes (clichés, stamps): matrix of intrauterine life violation; victim matrix; matrix of struggle; freedom matrix. The matrixes are laid during pregnancy, childbirth and the first stages of the postnatal period [7].

It has been noted that children who have been in comfortable psycho-emotional conditions during pregnancy and birth have higher initial mental potential than other infants. For example, separation from the mother immediately after birth has a negative impact on the child's willpower and perceptions of freedom and independence, which can be intimidating for these children. Parents' reluctance to have a child, especially if the mother demonstrates such reluctance, has an extremely negative psychological potential. So-called "accidental" children show decreased motivational activity, blurred purposeful attitudes and other problems.

Thus, prenatal and childbirth difficulties leave a deep mark on a person's developing psyche. 
This makes it more difficult for a person to adapt socially, and it makes it more difficult for the adult to communicate collectively in society, and so on. In order to avoid these kinds of difficulties it is necessary to work on several fronts at the same time. The first is family counselling, developing a culture of interpersonal communication in the family, deepening and stabilising family traditions. Secondly, there is the psychological and pedagogical activity of specialists in forming special respectful attitudes in society that welcome independent choice choice in respect of human health, and the formation of its foundations as early as the prenatal period prenatal period. In my opinion, a society whose world view is based on traditional family values and is now demonstrating promise.

\section{CONCLUSION}

To summarize the above, let us turn to the classical To summarize, we turn to the classical definition of family, which can be found in the modern philosophical dictionary: "Family is a small group based on marriage or blood kinship, the members of which are bound by the community of life, mutual moral responsibility and mutual assistance" [8]. It would seem that the definition sets common parameters that bind different people together: common moral rules, responsibility, mutual assistance. I also wholeheartedly agree with these parameters, but I want to emphasize that the basis of a family should be conscious spirituality, untiring growth of soul due to cares and efforts of each family member, voluntary service to each other. It is with this approach that the family can be seen as a kind of small school of Love.

\section{REFERENCES}

1. K. B. Murotmusaev "Psychological Aspects Of Human Health And The Power Of Love" The American Journal of Applied sciences Published: February 25, 2021 Pages: 73-77, Doi:

https://doi.org/10.37547/tajas/Volumeo3Iss ue02-07

2. Hazrat Inayat Khan Purification of the Mind I Hazrat Inayat Khan. - Moscow: Sphere, 1999.

3. Official website of Dr. K.B. Murotmusayev. - Access mode: www.dr-kamilbarlos.com.

4. Gatash V. Life before life [Electronic document] / Gatash V. // Zerkalo nedeli. - 17 June 2002. - №20 (395). - Access mode: http://www.zn.ua/3000/3450/34926/.

5. Livshits V.M. Perinatal psychology [Electronic document] / Livshits V.M. Mode of access: http://www.psychologyonline.net/articles/doc-475.html.

6. Web-site of the journal "Perinatal psychology and psychology of parenthood". - Access mode: http://www.psymama.ru/psycholog/index. html.

7. Website of the interregional scientific centre for pre- and perinatal development "Blagovest". - Access mode: http://congress2007.perfectbaby.ru/.

8. Grof Stanislaw Stanislav Areas of human unconscious [Electronic document] / Grof Stanislav. - Access mode: http://psylib.org.ua/books/grofs01/index.ht $\mathrm{m}$.

9. Newest Dictionary of Philosophy / Compiled by. A.A. Gritsanov. - Mn.: Publishing house of V.M. Skakun, 1998. 896c. 